SESSION \# 1526 DELOS

\title{
Functional Modules for Teaching Mechatronics to non-EE Engineering Students
}

\author{
Victor Giurgiutiu and Brian Mouzon \\ Department of Mechanical Engineering, University of South Carolina \\ Columbia, SC 29208, victorg@sc.edu
}

\begin{abstract}
The Department of Mechanical Engineering of the University of South Carolina has embarked upon a project to enhance the Mechatronics education of non-EE engineering students. NSF funds the project with cost-share by the Department of Mechanical Engineering and the College of Engineering and Information Technology. An essential part of this project is the construction of functional modules for teaching hands-on skills related to the interfacing of mechanical, electrical, and electronic components of a Mechatronics system. Non-EE engineering students have the need for hands-on experience to increase their ability and confidence in tackling electrical and electronics concepts, especially during the realization phase of a Mechatronics project. To address this need, we started developing a suit of functional teaching modules. These functional modules are intended as bolt-on building blocks with clearly defined inputs and outputs, and an explanation of the underlying operational principles. The students are expected to use the functional modules as a learning tool. After understanding their functionality, they are expected to duplicate the circuitry on their own breadboards to be incorporated into their Mechatronics class projects, as well as into other hands-on projects, as appropriate.
\end{abstract}

\section{INTRODUCTION}

\section{THE NEED FOR MECHATRONICS EDUCATION}

Due to the accelerated growth of electronics, computers and information technology industries, a hiatus has emerged between the teachings of traditional non-EE engineering education (e.g., Mechanical Engineering, Civil Engineering, Chemical Engineering, etc.) and the skills expected of non-EE graduates entering the job market. A recent job announcement for hiring a mechanical engineering graduate states "immediate opening for a Mechanical Design Engineer: broad knowledge in mechanical design and two or more of the following disciplines is required: electro-mechanical devices (preferably piezoelectric), opto-mechanics, precision components and mechanisms; must have demonstrated capabilities in the use of computer-aided engineering systems." A deluge of computers, sensors, microcontrollers, actuators has permeated the very fabric of present-day society. Microcontroller-based devices and appliances are to be found in all the crevices of our everyday life. Even the auto industry, a traditional mechanical engineering fiefdom, is putting tens of microcontrollers in a modern automobile, and plans to increase this 
number multifold as new technologies are being introduced. As revealed by a recent site visit to our university by BMW auto plant representatives, hybrid propulsion, 42-Volts wiring, "steerby-wire", "brake-by-wire", collision avoidance, autopilot, etc. are being currently developed, and automobiles with such capabilities will hit the market in the near future.

\section{MECHATRONICS EdUCATION IN US AND WORLD WIDE}

However, traditional engineering education of students covers only minimally electrical, electronics, and information technology instruction. The "high-tech" components of non-EE education are much below expectations, in spite of clear demand. Because of this disparity, the non-EE engineering graduates entering the job market are at a considerable handicap. To acquire high-tech skills required in the job market place, some non-EE students try to register in upperdivision EE courses. However, lacking the proper lower-division background, this practice puts them at a disadvantage, and negatively affects their GPA and course load. In response to this situation, an interdisciplinary engineering branch, that spans mechanical engineering, electronics, embedded microcontrollers/digital signal processing, controls, and information technology, has emerged under the name of Mechatronics. At close examination, one cannot but notice that most of today's machinery, from the simplest bread maker and robotics toys, through automobiles and manufacturing facilities contain at least one mechatronics component, whether overt or covert. Nationwide, efforts to introduce mechatronics education in non-EE curriculum have sprung in over twenty US universities, and several worldwide (Carryer, 2000; Craig, 2000; Field et al., 2000; Furman et al., 2000; Gardner, 2000; Giurgiutiu et al.; 2001; Hargrove, 2000; Hayden, 2001; Johnson, 2000; Lima et al., 2000; Luecke, 2001; Lyshevski, 2001; Sanoff, 2001; Shetty et al., 2000; Wild, 2001).

\section{The Need for Mechatronics Education in South Carolina}

At the University of South Carolina, the non-EE engineering students also have an acute need for education in the interdisciplinary field of mechatronics/microcontrollers. The state of South Carolina is going through an intense economical development effort focused on high-tech businesses and companies. This effort is aimed at bridging the technological divide that has placed South Carolina among the last in the nation in high-tech economy. Critical to this statewide effort, is the development of an adequate cadre of well trained personnel that can "hit the ground running" in the growing technology-oriented job market. Akin to similar effort going on in other places (e.g., Southern California), this will permit the building of "a critical mass of talent that local companies can draw from" (Brindley, 2001).

\section{Microcontroller/Mechatronics Education in the Department OF Mechanical ENGINEERING AT THE University OF SOUTH CAROLINA}

The Department of Mechanical Engineering at the University of South Carolina (DME-USC) is well positioned to participate in promoting and developing this emerging engineering education field. DME-USC established a course for teaching microcontrollers to mechanical engineering students - EMCH 367, www.me.sc.edu/courses/emch367. The course consists of four major components: (a) classroom instruction; (b) homework; (c) laboratory; (d) project. The classroom instruction is focused on instilling in students the basic knowledge related to programming and using the microcontroller. Part of the classroom instruction is performed in a computer laboratory, where the students interact with simulation software on a one-on-one basis. The homework is focused on the students' understanding and retention of the concepts in a selfteaching style, and it consists of examples that student follow and exercises that the students perform and return to the Teaching Assistants via email. The laboratory consists of five sessions 
that gradually take the students from simple microcontroller programming through the usage of its various functions such as parallel ports, serial communication, event timing (detection and generation), DC motor tachometer, stepper motor control, and analog-to-digital conversion. The capstone of the course is a one-month project period in which the students work in pairs to achieve the development, design, coding, construction, and demonstration of a microcontrollerbase project of their own choice. The project culminates with a written report, an oral presentation, and a hands-on demonstration. Please refer to the course website www.me.sc.edu/courses/emch367 for samples of past projects.

The engineering students at the University of South Carolina, of which $22 \%$ are women and $30 \%$ are minority, are in dire need of support to expand and enhance the mechatronics/microcontroller education. The project currently undertaken with NSF support will empower the University of South Carolina engineering students with the knowledge and hands-on experience required for success in today's technologically competitive economy and market place.

\section{FUNCTIONAL MODULES OVERVIEW}

An essential part of this project is the construction of functional modules for teaching hands-on skills related to the interfacing of mechanical, electrical, and electronic components of a Mechatronics system. An essential need of non-EE engineering students is for hands-on experience to increase their ability and confidence in tackling electrical and electronics concepts, especially during the realization phase of a Mechatronics project. To address this need, we started developing a suit of functional teaching modules. The modules to be developed will include: (a) voltage division; (b) op-amp signal amplifiers; (c) opto-electronic sensors; (d) on/off (field-effect MOSFET) power amplifiers; (e) linear power amplifiers; (f) pulse-width modulation dc motor drive units; (g) stepper motor drive units; (h) AC-DC converters; (i) temperature sensors; and (j) humidity sensors. Accompanying the functional modules will be electrical and component schematics, applicable equations, and a full experimental report containing calibration results. Thus, the students will know what results to expect when using the functional module. These functional modules are intended as bolt-on building blocks with clearly defined inputs and outputs, and an explanation of the underlying operational principles. To achieve this, the functional modules are housed in transparent casings, which allow the students to see the actual electric/electronic components of the circuitry, and to compare this image with the intricacy of the circuit diagram. The students are expected to use the functional modules as a learning tool. After understanding their functionality, they are expected to duplicate the circuitry on their own breadboards to be incorporated into their Mechatronics class projects, as well as into other hands-on projects, as appropriate.

Our approach will help expand the student's understanding of hands-on Mechatronics concepts. Though developed in the Department of Mechanical Engineering, these concepts of functional modules will be shared with other engineering departments in order to provide a useful teaching aid.

\section{VOLTAGE DIVIDER}

Voltage division is an electrical concept that allows voltage to be varied according to two resistors in series. The change of an input voltage is important in electronics and mechatronics 
because different loads (e.g. DC motors, Operational-Amplifier, transistors) require certain voltages. To exceed the maximum voltage of a load can cause damage beyond repair. Therefore, voltage division is used in order to control the voltage that is supplied to a particular load.

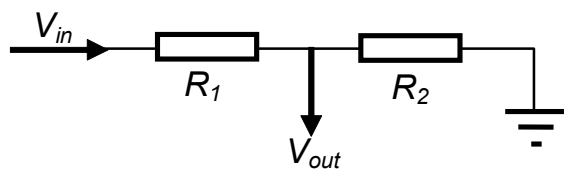

Figure 1. Voltage Divider Circuitry (No Load)

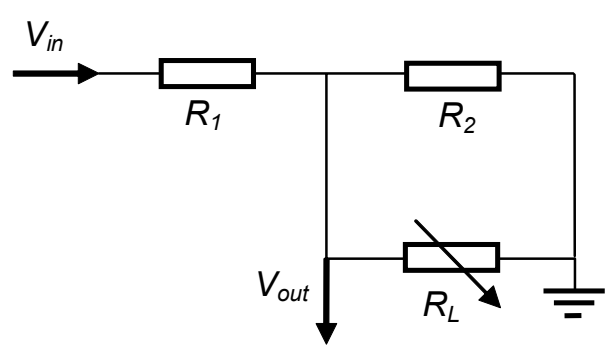

Figure 2. Voltage Divider Circuitry (With Load)

A simple open-circuit (Figure 1) can be used to demonstrate the principles of voltage division. In an open-circuit, the current through all components remains constant. According to Kirchoff's Voltage Law (KVL), the sum of the voltage drops across each resistor is equal to the total voltage drop of the circuit. Additionally, resistors in series have a total resistance equal to the sum of the resistances. An analysis of this circuit can be performed using Ohm's Law,

$$
V=I R
$$

where $V$ is voltage, $I$ is current, and $R$ is resistance. Applying a constant current to Ohm's Law yields,

and

$$
V_{l}=I R_{I}
$$

Combining Ohm's Law with KVL, we see,

$$
V_{2}=I R_{2}
$$

$$
V=I\left(R_{1}+R_{2}\right)
$$

From inspection of the voltage divider circuit (Figure 1), $V_{\text {out }}$ is equal to $V_{2}$. Solving equation (4) for the current $(I)$ and back substituting it into equation (3), we are able to solve for the theoretical output voltage,

$$
V_{\text {out }}=V_{2}=\frac{R_{2}}{R_{1}+R_{2}} V=\frac{1}{1+\frac{R_{1}}{R_{2}}} V
$$

where $V$ is the input voltage, $V_{i n}$. From equation (5), we can observe that the output voltage is the input voltage times the ratio of the second resistor to the sum of the resistors.

When a load is applied in parallel with the second resistor (Figure 2), the circuit becomes closed. In this case, the current through the circuit is affected. The equivalent resistance of the load and the second resistor can be determined by:

$$
\frac{1}{R_{2, L}}=\frac{1}{R_{2}}+\frac{1}{R_{L}}
$$


The total resistance, $R$, of the circuit is:

$$
R=R_{1}+\frac{1}{\frac{1}{R_{2}}+\frac{1}{R_{L}}}
$$

Substituting Equation (7) into Ohm's Law yields:

$$
I=\frac{V_{\text {in }}}{R}
$$

The output voltage can be found by assuming the input voltage is multiplied by a factor of the resistor-influenced values, which is to say:

$$
V_{\text {out }}=\frac{R_{2} R_{L}}{R_{1} R_{2}+R_{1} R_{L}+R_{2} R_{L}} V_{\text {in }}=\frac{\frac{R_{L}}{R_{1}}}{1+\frac{R_{L}}{R_{2}}+\frac{R_{L}}{R_{1}}} V_{\text {in }}
$$

Experimental results show the validity of the theory described above. For all experimentation, an input voltage of $5 \mathrm{~V}$ was used. Figure (3) is the graph of data collected when a voltage divider has no load. To collect this data, both resistances were varied and the output voltage was measured. The plot is similar to one for Equation (5). Figure (4) is a graph of data collected for a voltage divider under a variable load. This data was collected by keeping $R_{1}$ and $R_{2}$ constant and varying the load by using a rheostat (see Figure 2). This plot is also the expected result for Equation (9). One notices that for high loading $\left(\mathrm{R}_{\mathrm{L}} \rightarrow 0\right)$, the output voltage vanishes $\left(\mathrm{V}_{\text {out }} \rightarrow 0\right)$. As the loading decreases $\left(\mathrm{R}_{\mathrm{L}} \rightarrow \infty\right)$, the current drawn by $\mathrm{R}_{\mathrm{L}}$ diminishes and the output voltage approaches the no-load value.

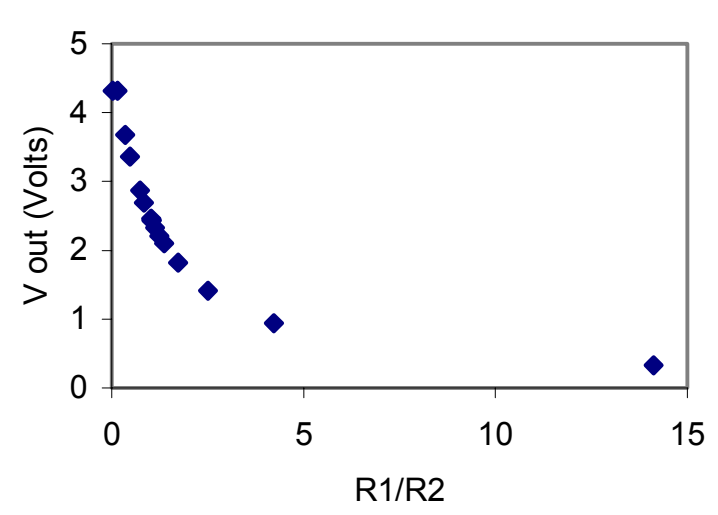

Figure 3. Voltage Divider (No Load)

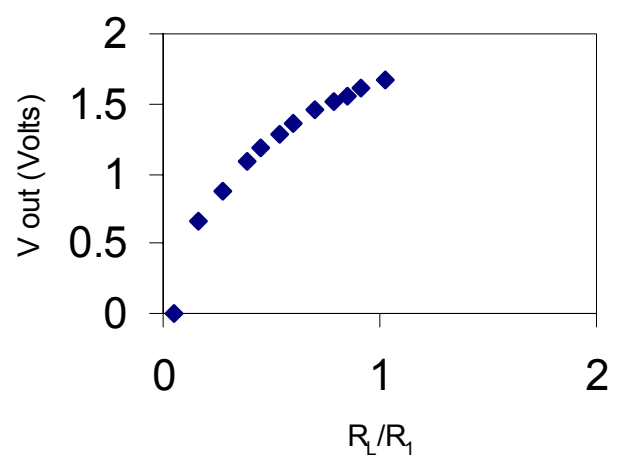

Figure 4. Voltage Divider (With Variable Load) 


\section{OP-AMP SIGNAL AMPLIFIER}

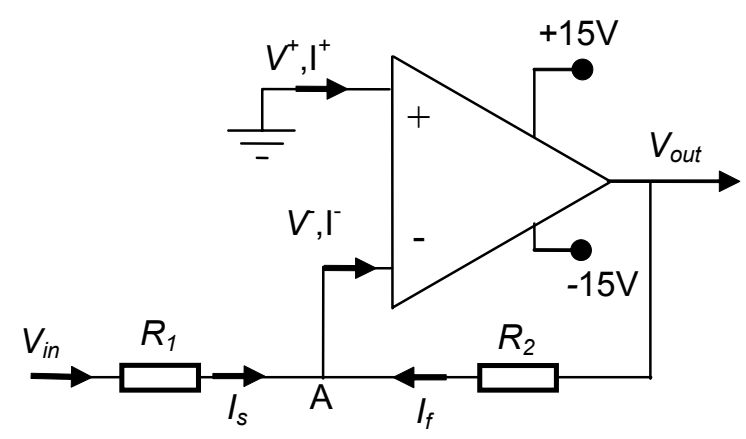

Figure 5. Inverting Op-Amp Circuitry

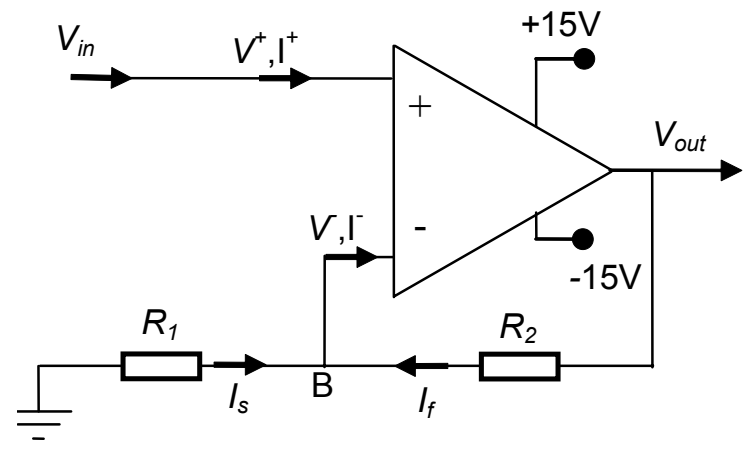

Figure 6. Non-Inverting Op-Amp Circuitry

An operational amplifier is an electronic device used to boost an input signal to a desired output level. It is an integrated circuit, since transistors, resistors, and capacitors are used for its composition. An external power source is required to allow signal amplification; therefore, the op-amp is an active device. The power source also acts to limit the expected gain applied to an input signal, as the output signal cannot exceed the voltage supplied to the op-amp. In reality, the saturation voltage will be less than the voltage supplied due to the power required to run the opamp, as well as source losses.

For the purposes of this paper, two types of op-amp signal amplifiers were analyzed. Both types amplify signals, as their names suggest, but the output polarity of the inverting op-amp is the inverse of the input signal. Conversely, the input signal of the non-inverting op-amp is not inverted to produce the output signal.

The op-amp works on the two basic principles. First, an infinite gain is achieved within the device; therefore, the differential input voltage is zero. Symbolically, this reduces to:

$$
V^{+}=V
$$

where $V^{+}$is the non-inverting input voltage and $V$ is the inverting input voltage. The second rule that op-amps follow is no current is drawn by either input circuit because there is infinite impedance at the inputs. Therefore,

$$
I^{+}=I^{=0}
$$

where $I^{+}$and $I$ correspond to the input currents of the non-inverting and inverting op-amps, respectively.

Central to the performance of an op-amp is a loop from the output voltage back to the inverting input voltage. Known as feedback, this forms a closed-loop, which helps maintain stability and control gain of the op-amp. It is also used in the circuitry analysis to predict how the device will work. 


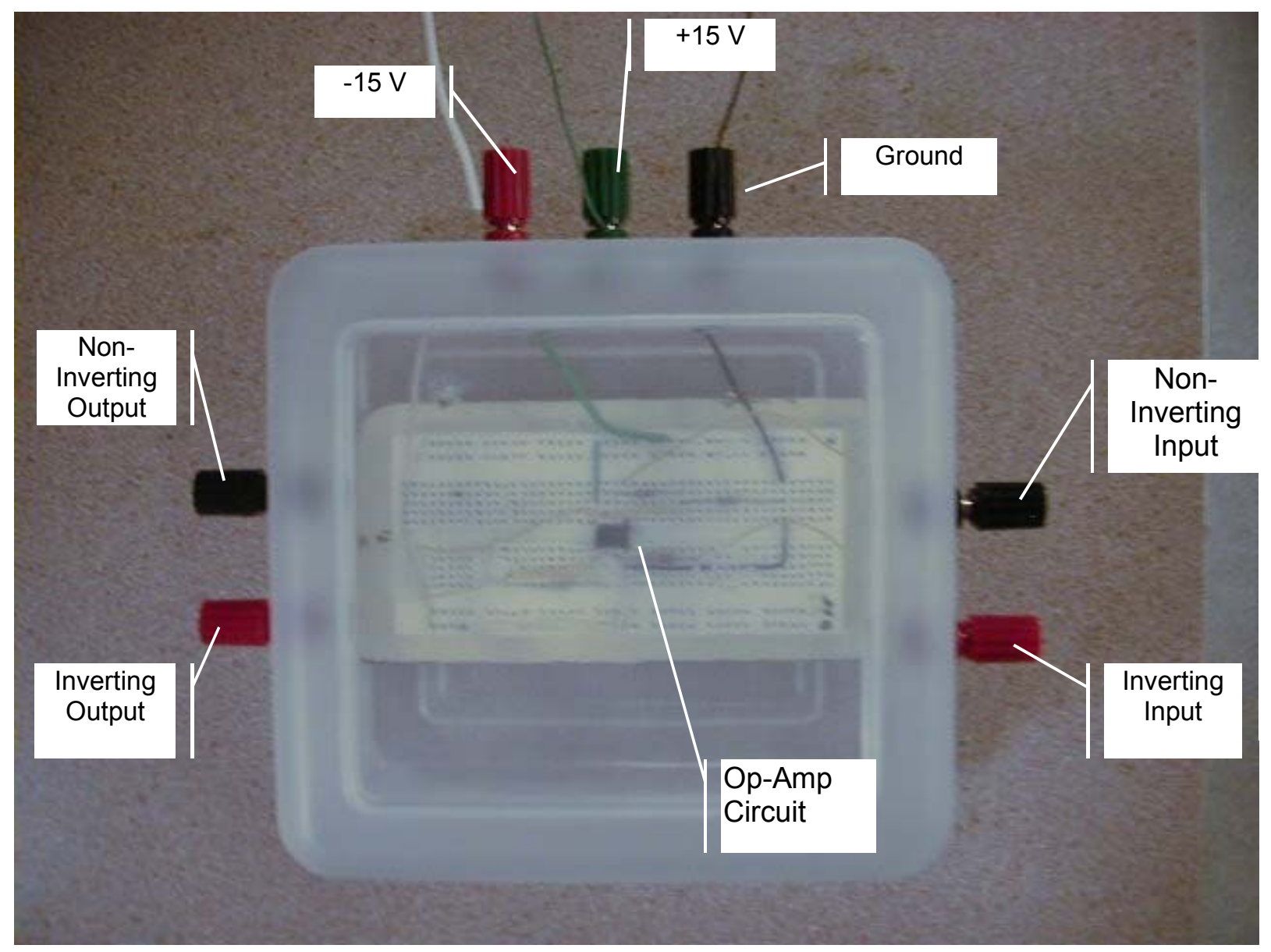

Figure 7. Op-Amp Functional Module

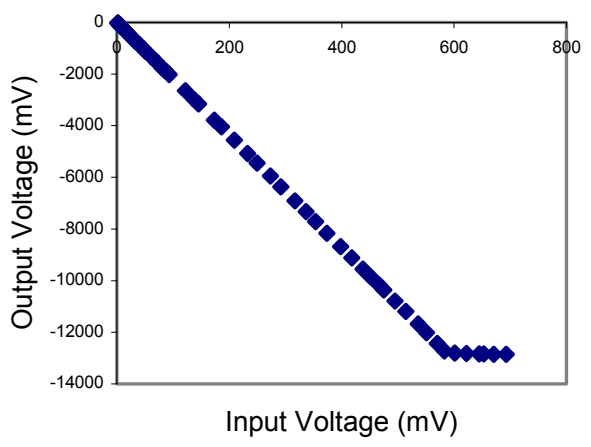

Figure 8. Inverting Op-Amp Output Voltage

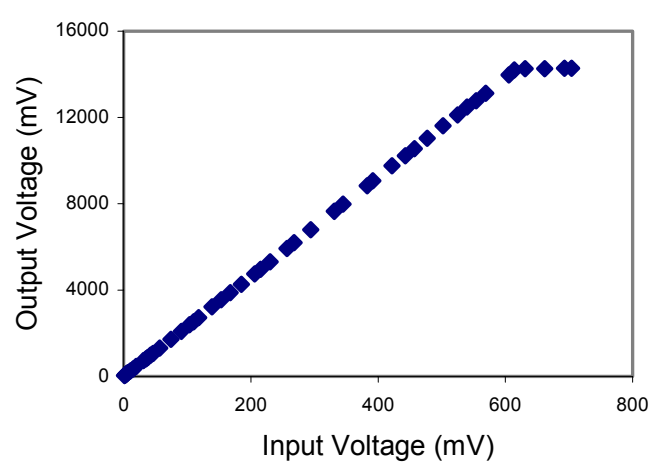

Figure 9. Non-Inverting Op-Amp Output Voltage

An analysis of the inverting op-amp circuitry gives an expression for the expected gain and the output voltage. Using Kirchoff's Current Law (KCL) with reference to node A (Figure 5) gives, 


$$
I_{s}+I_{f}=I_{\text {in }}
$$

where $I_{s}$ is the source current, $I_{f}$ is the feedback current, and $I_{\text {in }}$ is the op-amp input current. Equation (9) shows that $I_{\text {in }}$ is equal to zero; therefore, the feedback current is equal to the negative of the source current. Applying Ohm's Law to the above,

$$
\frac{V_{\text {in }}}{R_{1}}=-\frac{V_{\text {out }}}{R_{2}}
$$

Solving for the output voltage yields,

$$
V_{\text {out }}=-\left(\frac{R_{2}}{R_{1}}\right) V_{\text {in }}
$$

with the gain being represented by the negative ratio of $R_{2}$ to $R_{1}$.

Evaluating the non-inverting op-amp (Figure 6) about node B yields:

$$
I_{f}=I_{s}+I_{\text {in }}
$$

Once again, we assume that the current into the op-amp is zero; the source current is therefore equal to the feedback current. Appling Ohm's Law to both sides of Equation (13) gives,

$$
\frac{V_{\text {out }}-V_{\text {in }}}{R_{2}}=\frac{V_{\text {in }}}{R_{1}}
$$

Solving for $V_{\text {out }}$, we obtain

$$
V_{\text {out }}=\left(\frac{R_{2}}{R_{1}}+1\right) V_{\text {in }}
$$

with the gain being represented the sum of one plus the ratio of R2 to R1.

One additional key feature of the op-amp is that the output voltage will eventually reach a cut-off, or saturation, voltage. This voltage will always be less than the voltage supplied to run the opamp, due to internal losses and the power required to run the op-amp. This cut-off is shown graphically (Figures 8,9 ) as a "flat tail."

The practical realization of these concepts is shown in Figure (7), which presents the first functional module constructed under the current effort. In this picture, the op-amp circuitry, which is laid out on a breadboard, in encased in the clear housing. Terminal posts are bolted into the plastic sides of the housing, each color coded to match industry standards (i.e. "black" for ground, "yellow" for signal, "red" for $5 \mathrm{~V}$ input, etc.) Each post is connected on the inside of the housing to its corresponding location in the circuit. This allows a student to view and connect directly to the op-amp by way of the terminal posts. The tests performed on this functional module showed good agreement with the predicted results (Figures 8, 9). 


\section{FIELD EFFECT POWER AMPLIFIERS}

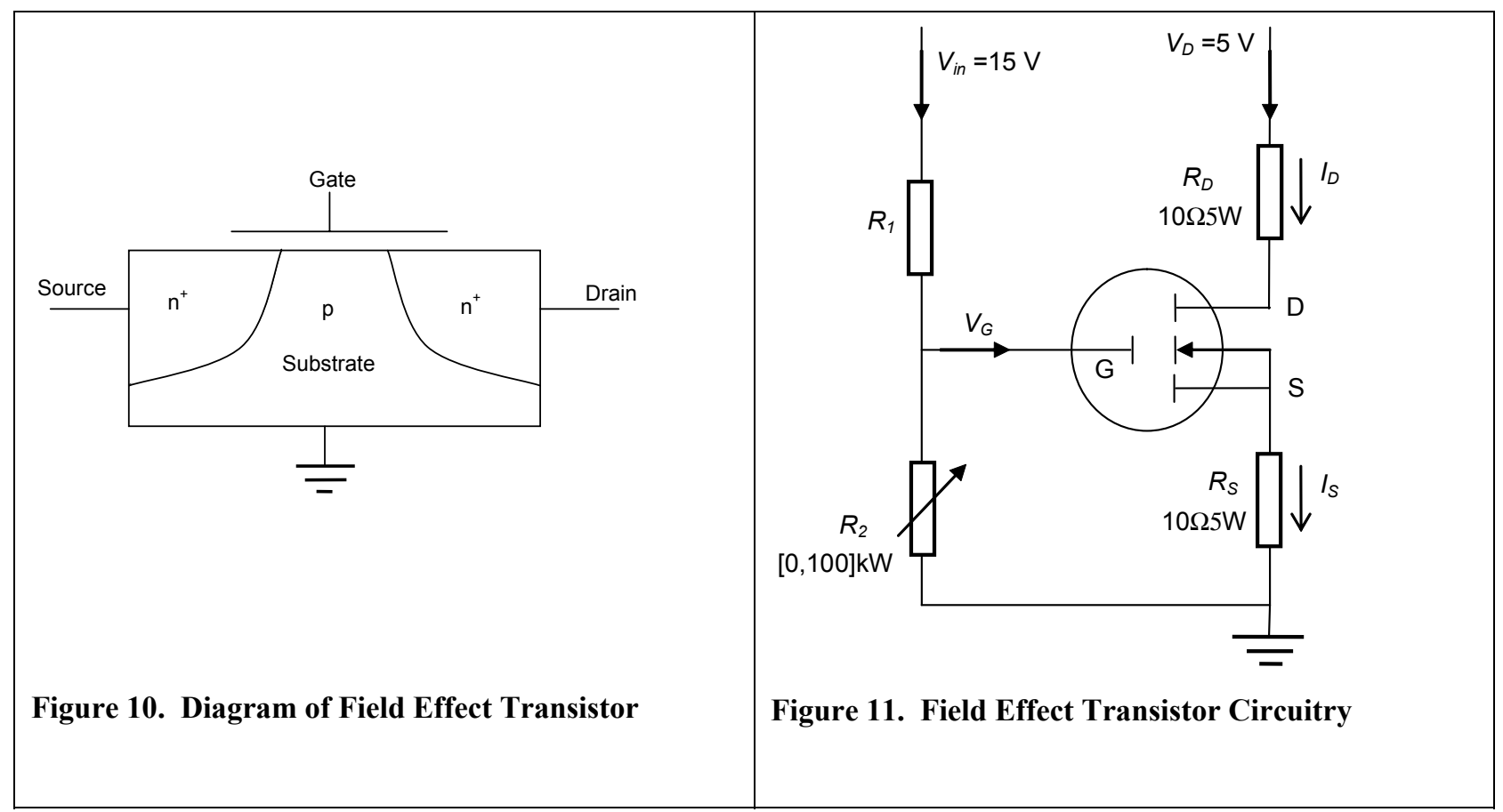

Field effect transistors (FET) come in a variety of configurations, but they all work on the same basic principles. The type of FET (IRF 530) used for this research was the metal-oxidesemiconductor (MOSFET). MOSFET's are comprised of two basic materials, $n$ and $p$, which designates their method of conduction. The $n$-type semiconductor has an abundance of electrons and conduct through the movement of these electrons, while the $p$-type semiconductor allows current to flow by means of drifting holes. The set-up of an individual transistor, with relation to the types of semiconductors that comprise it, helps determine the method of operation.

An n-p-n configuration, shown in Figure (10), is used for the IRF 530. One $n+$ region is connected to the drain, which has a voltage applied to it. The other $\mathrm{n}+$ region is connected to the source and it goes to ground. Ground is also attached to the p-type substrate. This is represented by the right side of Figure (11). When no other voltage is applied to the transistor, there is no transfer of electrons from the drain to the source. This state is the normal condition for the transistor and is known as the off state. The electrons of the p-type substrate are attracted to the gate surface by applying a voltage to the gate. These electrons form an n-channel, which allows current to flow from the drain to the source. The voltage that allows the n-channel to form is known as a threshold voltage, VT.

As the gate voltage increases, the size of the channel also increases, allowing more current to flow. There is a limitation on how much gate voltage can be applied to the MOSFET. As a voltage is applied, the n-channel opens to various depths between the drain and the source junctions. This is due to the difference in potential at each location (the source going to ground and the drain having a voltage supply). The channel at the drain does not reach the same depth as the source and, therefore, as the voltage increases, runs the risk of cutting the current flow. This occurrence is known as a pinch off and it takes place where the gate voltage is twice the threshold voltage, or, 


$$
V_{G} \geq 2 V_{T}
$$

The area above the threshold voltage and below the point where the MOSFET reaches saturation is know as the ohmic region, because it adheres to Ohm's Law. Since a certain gate voltage is required to create a channel, the difference between the gate and threshold voltages is considered the output of the transistor.

$$
V_{G}-V_{T}=V_{s}
$$

This output is the voltage found at the source terminal, $V_{s}$. Assuming a static source resistance, $R_{s}$, Ohm's Law can be used to find the source current, $I_{d s}$,

$$
I_{d s}=\frac{V_{G}-V_{T}}{R_{s}}
$$

The threshold voltage can be considered equal to the drain voltage, $V_{D}$. Therefore, it is possible to note that when the gate-to-drain potential is zero, the source current is likewise zero. Data collected on the MOSFET is graphed (Figure 12) and the results verify Equation (18).

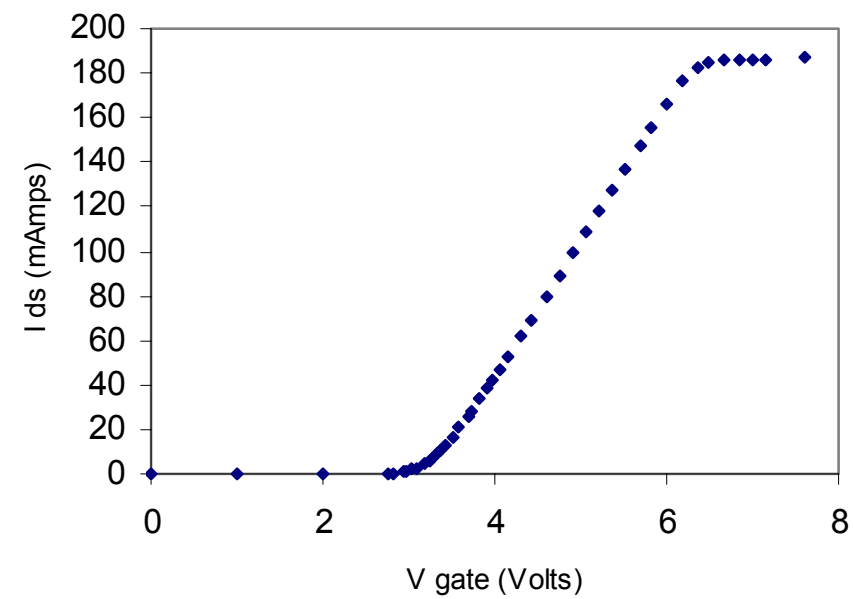

Figure 12. IRF 530 Experimental Data

\section{POWER AMPLIFIER}

A transistor can be used to amplify a signal in four modes: as a voltage -controlled voltage amplifier, as a voltage-controlled current amplifier, as a current-controlled voltage amplifier, and as a current-controlled current amplifier. The transistors are composed of three parts-the base (B), the collector (C), and the emitter (E)-as shown in Figure (13). For experimentation purposes, the TIP 120 transistor was used. This particular component is actually two transistors, which form a configuration known as a Darlington-pair transistor. Figure (13) shows how the collectoremitter voltage from the first transistor triggers the second transistor. 


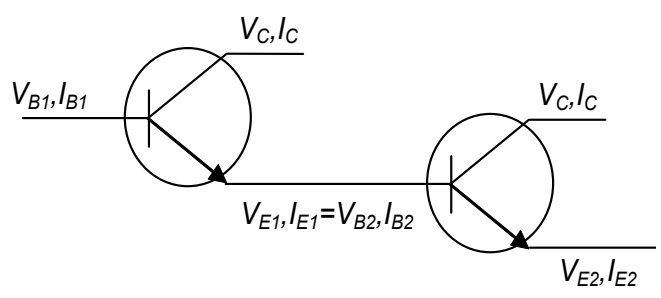

Figure 13. Darlington Pair Transistors

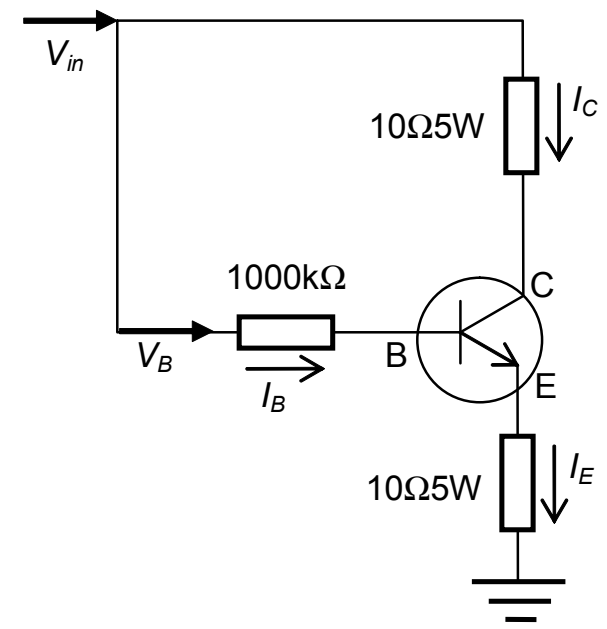

Figure 14. Power Amplifier Circuitry

The transistor, as a power amplifier, utilizes a base current and voltage, which control the collector current. Like the MOSFET, the TIP 120 transistor is composed of a three layer chemical material, known as npn. When current flows from the base to the emitter, the electrons fill the holes in the $p$ layer, allowing the electrons in the layer to move towards the positively charged $n$ layer at the emitter. When current flows from the collector to the emitter, the holes in the $p$ layer are emptied and the electrons are collected and sent as a current.

For power amplification transistors (Figure 14), a set of collector characteristic curves are used in order to determine a maximum gain factor, $\beta$. This gain is used to increase the base current, $I_{B}$, to equal the collector current, $I_{C}$. In $n p n$ transistors, a flow of electrons towards the emitter is preferable. Therefore, the emitter current, $I_{E}$ is equal to the sum of the base current and the collector current.

$$
I_{E}=I_{C}+I_{B}
$$

Substituting $I_{B} \beta$ in for $I_{C}$, a linear amplification for a single transistor is noticed (Equation 20).

$$
I_{E}=I_{B}(1+\beta)
$$

Since the TIP 120 transistor is two transistors, a relationship must be found from Equation (20). The emitter current found is equal to the base current that goes into the second transistor, $I_{B 2}$. Once again, using Equation (19) yields:

$$
I_{E 2}=I_{B 2}+I_{C 2}
$$

Substituting and simplifying gives an equation for calculating the final emitter current,

$$
I_{E 2}=I_{B 1}(\beta+1)^{2}
$$

The final gain of the base current is shown in Equation (22) to be a function of the square of the gain. This is validated by the experimental data that was collected and graphed (Figure 15). The gain is very small until the transistor reaches a threshold. At this point, the emitter current goes up drastically until it reaches a saturation current, where it levels back off again. 


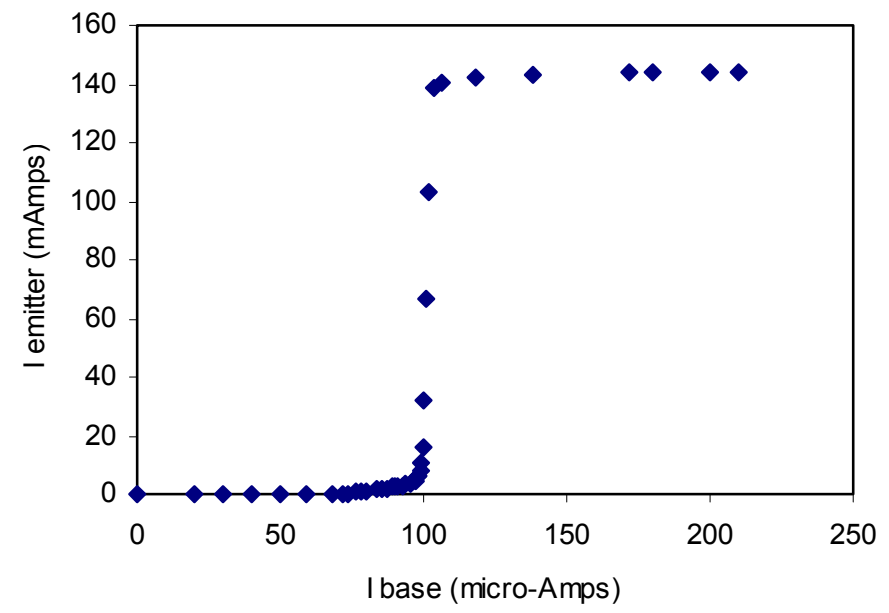

Figure 15. TIP 120 Experimental Data

\section{PULSE-WIDTH MODULATION}

The input voltage to a DC motor directly influences the speed and torque of the motor. Conventional means of controlling the voltage involved the use of a variable resistor to limit the input. By altering the voltage, the output speed changed. This approach lacked a feedbackresponse exchange. Pulse-width modulation (PWM) uses such an interaction to achieve a desired output. By incorporating emitter-detectors, op-amps, and transistors, a microcontroller is able to detect and vary the speed of a DC motor.

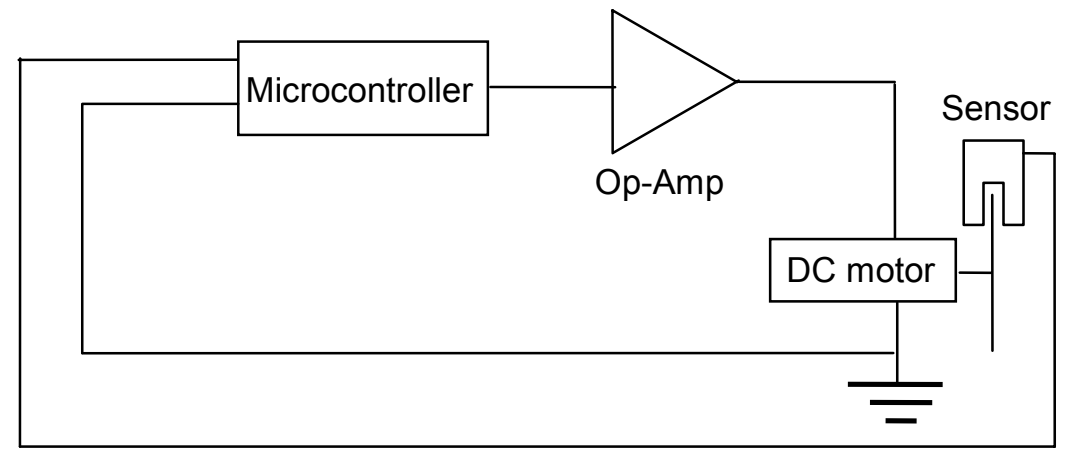

Figure 16. Simple Pulse-Width Modulation Schematic

To understand how PWM works, it is first necessary to observe a square wave and make an analysis with regards to a duty cycle. A square wave (Figure 17) can be used to control a DC motor. There are two simple features of a square wave. The "high" level indicates a maximum voltage being sent, or in the case of PWM 5 Volts. The "low" level sends a minimum voltage, or 1 Volt for PWM. The wave operates essentially like a switch, either "on" or "off". Another 
important property of the square wave is what is known as the "duty cycle", which is defined as a ratio of $t$ to $T$ (with reference to Figure 17).

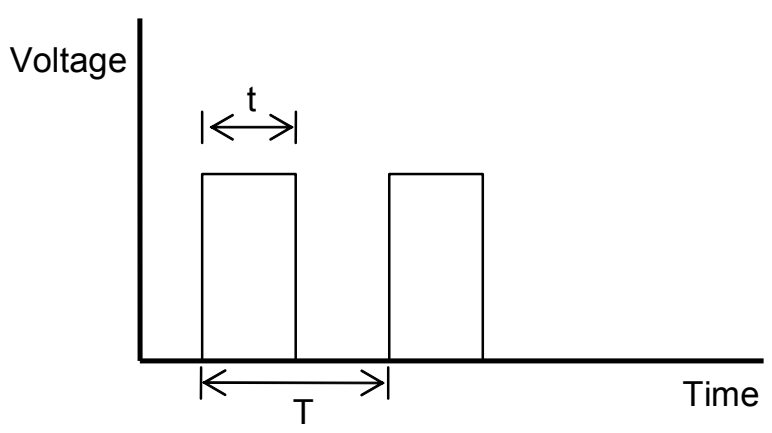

Figure 17. Square Wave

In order for PWM to operate effectively, a number of electronic components must be tied together. This link tasks place in the microcontroller, which receives, compares, and transmits signals. As the motor rotates a shaft, a sensor of some type (e.g. emitter-detector) is used to measure a specified output. This measurement is sent back to the microcontroller in the form of a square wave. The signal is compared to an optimum set point and the microcontroller sends out a response signal to the motor. This is the wave that is pulsing as needed in order to control the output of the motor. In the simplified circuit used for this experiment (Figure 16), an operational amplifier was used in order to boost the signal to the motor. Additional devices, such as transistors, can be used at other locations to amplify signals as needed.

\section{CONCLUSIONS}

Many universities have started offering courses on Mechatronics to undergraduate and graduate students. Such courses, cutting across departmental boundaries and combining theory, hands-on experiments, and technology applications, greatly benefit the undergraduate students, graduate students, and even faculty. They propel the curriculum towards the forefront of engineering education and directly answer the training and education challenges of the $3^{\text {rd }}$ millennium.

The Department of Mechanical Engineering of the University of South Carolina has embarked upon a project to enhance the Mechatronics education of non-EE engineering students. This project is funded by the NSF with cost-share from the Department of Mechanical Engineering and the College of Engineering and Information Technology.

An essential part of this project is the construction of functional modules for teaching hands-on skills related to the interfacing of mechanical, electrical, and electronic components of a Mechatronics system. Non-EE engineering students have the need for hands-on experience to increase their ability and confidence in tackling electrical and electronics concepts, especially during the realization phase of a Mechatronics project. To address this need, we started developing a suit of functional teaching modules. These functional modules are intended as bolt- 
on building blocks with clearly defined inputs and outputs, and an explanation of the underlying operational principles. The students are expected to use the functional modules as a learning tool. After understanding their functionality, they are expected to duplicate the circuitry on their own breadboards to be incorporated into their Mechatronics class projects, as well as into other hands-on projects, as appropriate.

To address this need, we started developing a suit of functional teaching modules. The modules to be developed will include: (a) voltage division; (b) op-amp signal amplifiers; (c) optoelectronic sensors; (d) on/off (field-effect MOSFET) power amplifiers; (e) linear power amplifiers; (f) pulse-width modulation dc motor drive units; (g) stepper motor drive units; (h) AC-DC converters; (i) temperature sensors; and (j) humidity sensors. Accompanying the functional modules will be electrical and component schematics, applicable equations, and a full experimental report containing calibration results. Thus, the students will know what results to expect when using the functional module. The present paper has presented our results in the development, testing, and documentation of the following functional modules: (a), (b), (d), (e), and (f).

The work on this project is continuing, and further developments will be reported in future publications.

\section{ACKNOWLEDGEMENTS}

The financial support of the National Science Foundation, under contract NSF-DUE \#0126966, is greatly appreciated. Additionally, the work of a summer student, Alexander Kloth, was of tremendous assistance in writing the paper.

\section{REFERENCES}

Brindley, D. (2001) “A Big Picture Guy - Interview with Broadcom, Inc., Co-founder Henry Samueli”, Prism, American Society for Engineering Education, April 2001, pp. 16-21.

Carryer, J. E. (2000) "March Madness: a Mechatronics Project Theme", Mechatronics 2000 - 7th Mechatronics Forum International Conference, September 6-8, 2000, Atlanta, GA, CD-ROM.

Craig, K. (2000) "Inverted Pendulum Systems: Rotary and Arm-Driven - a Mechatronics System Design Case Study", Mechatronics 2000 - 7th Mechatronics Forum International Conference, September 6-8, 2000, Atlanta, GA, CD-ROM.

Field, S.; Meek, S.; Devasia, S. (2000) "Mechatronics Education in the Department of Mechanical Engineering at the University of Utah", Mechatronics 2000 - 7th Mechatronics Forum International Conference, September 6-8, 2000, Atlanta, GA, CD-ROM.

Furman, B. J.; Hayward, G. P. (2000) “Asynchronous Hands-on Experiments for Mechatronics Education”, Mechatronics 2000 - 7th Mechatronics Forum International Conference, September 6-8, 2000, Atlanta, GA, CD-ROM.

Gardner, J. F. (2000) “Two Projects for Undergraduate Mechatronics Class: Success and Failure”, Mechatronics 2000 - 7th Mechatronics Forum International Conference, September 6-8, 2000, Atlanta, GA, CD-ROM. 
Giurgiutiu, V.; Bayoumi, A. E.; Nall, G. (2002) "Mechatronics and Smart Structures - Emerging Engineering Disciplines of the Third Millennium", Journal of Mechatronics, Pergamon Press, UK, Vol. 12, No. 2, March 2002, pp. 169-181

Hargrove, J. B. (2000) "Student Projects for Mechatronics Education in the Core Curriculum at Kettering University", Mechatronics 2000 - 7th Mechatronics Forum International Conference, September 6-8, 2000, Atlanta, GA, CD-ROM.

Hayden, T. (2001) “The Age of Robots”, US News \& World Reports, April 23, 2001, pp. 45-50.

Histand, M. B., Alciatore, D. G., (1999) Introduction to Mechatronics and Measurement Systems. McGraw-Hill Companies, Inc., Boston.

Johnson, C. W. (2000) “Mechatronics Education: Where are We and Where Are We Headed?", Mechatronics 2000 7th Mechatronics Forum International Conference, September 6-8, 2000, Atlanta, GA, CD-ROM.

Lima, M.; Gomes, M. P.; Putnik, G.; Silva, S.; Monteiro, J.; Couto, C. (2000) "Mechatronics Education at the University of Minho", Mechatronics 2000 - 7th Mechatronics Forum International Conference, September 6-8, 2000, Atlanta, GA, CD-ROM.

Luecke, G. R. (2000) "Multi-tiered Control for Undergraduate Mechatronics", Mechatronics 2000 - 7th Mechatronics Forum International Conference, September 6-8, 2000, Atlanta, GA, CD-ROM.

Lyshevski, S. E. (2000) “Mechatronics and New Directions in Engineering Education”, Mechatronics 2000 - 7th Mechatronics Forum International Conference, September 6-8, 2000, Atlanta, GA, CD-ROM.

Rizzoni, G. (2000) Principles and Applications of Electrical Engineering. McGraw-Hill Companies, Inc., Boston.

Sanoff, A. P. (2001) "Closing the Digital Divide", Prism, American Society for Engineering Education, April 2001, pp. 16-21.

Shetty, D.; Kolk, R.; Kondo, J.; Campana, C. (2000) "Mechatronics Technology Demonstrator - An Educational Experience", Mechatronics 2000 - 7th Mechatronics Forum International Conference, September 6-8, 2000, Atlanta, GA, CD-ROM.

Wild P. M.; Surgeor, B. W.; Zak, G. (2000) “The Mechatronics Laboratory Experience”, Mechatronics 2000 - 7th Mechatronics Forum International Conference, September 6-8, 2000, Atlanta, GA, CD-ROM.

\section{BIOGRAPHIES}

Victor Giurgiutiu PhD graduated from Imperial College, London University, England in 1972 with a major in Aeronautical Engineering. In 1977 he received from the same college a Ph.D. in Aeronautical Structures, with the thesis titled "Vibrations and Dynamic Stability of Rotor Blades". For the next 15 years he worked in Romania on aeronautical teaching and research, being connected with the building of several fixed and rotary wing aircraft, under British and French license, as well as of Romanian design. In the period 1992-1996, he was Visiting and then Research Professor at Virginia Polytechnic Institute and State University. Presently, he is Associate Professor in the Department of Mechanical Engineering at the University of South Carolina. He maintains a broad interest in many areas of applied mechanics with special focus on adaptive materials, smart structures, and mechatronics.

BRIAN MOUZON is an Undergraduate Student in the Department of Mechanical Engineering at the University of South Carolina in Columbia. Under the mentorship of Dr. Giurgiutiu, Brian has conducted research in the field of mechatronics. Following graduation in the spring of 2003, he will attend Graduate School, at a university to be determined, to pursue an advanced degree in the area of Fluid Mechanics and applications in biomedical technology. 